\title{
The Voice within the Voice of Monica Velásquez
}

Three Names for a Place, by the paceña, that is La Paz poet, Monica Velásquez, is a book that celebrates and suffers that which, coming from one's own being, one perceives as distinct from one's self. The Other is the enormous desire that impels this book from beginning to end. The poem tells of a girl, Magdalena, born to fill an empty name that was waiting for her. Destiny had preserved that name so that the girl could animate it. Sometimes Magdalena is a you and sometimes a third person, but always she is the other whom the poetic subject chooses to speak for herself.

A child loses the consciousness of milk

she recognizes

the tiny vacancies of helplessness

she runs through the forest

praying

that the mouth of God does not devour her.

God must fill himself with the girl who escapes, as the name Magdalena must fill itself with the poetic subject. Monica Velásquez has written a book of poems with an authentic lyric tension and a developed poetic: the word is a vast emptiness that calls out for the poetic subject which it absorbs so that it may be animated. Magdalena lives, dies, and is reborn through her name, like a language purified.

to fill the emptiness of a name

Magdalena

The book begins with a dedication "to my family/ to the magic" that refers, on the one hand, to that which precedes the subject and directs it, and on the other, to that which could free it. The epigraph from Clarice Lispector, "They gave me a name and alienated me from myself," signals the initial inquietude. The name imposes the destiny of the named because the word is performative and one realizes in it the desire of the other.

-Jorge Accame 